\title{
Validation of the TanDEM-X Intermediate Digital Elevation Model With Airborne LiDAR and Differential GNSS in Kruger National Park
}

\author{
H. Balzter, J. Baade, and K. Rogers
}

\begin{abstract}
The recently released TanDEM-X intermediate digital elevation model (IDEM) product by the German Aerospace Center (DLR) provides elevation models at 12-m spatial resolution and above. It was derived from bistatic synthetic aperture radar (SAR) interferometry using the two TerraSAR-X satellites flying in close constellation. The aim of this study was to validate the vertical accuracy of the IDEM data at study sites in the Kruger National Park, South Africa. Two validation locations are presented: a dried up former reservoir (Nhlanganzwani Dam) characterized by bare soil and grassland and the peninsula between the Sabie and Sand Rivers near Skukuza characterized by dense woody cover. The results show that the IDEM elevation data are affected by residual vegetation canopy height and landform features smaller than the IDEM resolution cell. The scattering phase centers are located in the canopy but at a lower height than the location of the LiDAR first return signal. When only LiDAR ground hits or differential GNSS ground survey points are used for comparison, the IDEM data have an rmse $<1 \mathrm{~m}$ and a small bias of less than $0.25 \mathrm{~m}$ in moderate terrain.
\end{abstract}

Index Terms-Accuracy, interferometry, surface topography, synthetic aperture radar (SAR), TanDEM-X, vegetation.

\section{INTRODUCTION}

D IGITAL elevation models (DEMs) represent fundamental data for a range of applications including Earth surface process studies in the field of ecology, geology, geomorphology, and hydrology, among others. For some countries, highresolution digital terrain models (DTMs) representing the solid Earth surface derived from topographic maps or aerial surveys (photogrammetry and laser) are available. However, for vast regions of the Earth, this fundamental data resource is missing. Thus, the past two decades have witnessed a continuous growth

Manuscript received July 13, 2015; revised October 27, 2015 and December 9, 2015; accepted December 14, 2015. Date of publication January 7, 2016; date of current version January 19, 2016. This work was supported in part by the German Aerospace Center (DLR), the Natural Environment Research Council's National Centre for Earth Observation, the Royal Society Wolfson Research Merit Award (H. Balzter, ref 2011/R3), and the German Research Foundation (DFG; J. Baade, ref BA 1377/12-1).

H. Balzter is with the Centre for Landscape and Climate Research, University of Leicester, Leicester LE1 7RH, U.K., and also with the National Centre for Earth Observation, University of Leicester, Leicester LE1 7RH, U.K. (e-mail: hb91@le.ac.uk).

J. Baade is with Friedrich-Schiller-University, 07743 Jena, Germany (e-mail: cub@uni-jena.de).

K. Rogers is with University of the Witwatersrand, Johannesburg 2001, South Africa (e-mail: kevin.rogers@wits.ac.za).

Digital Object Identifier 10.1109/LGRS.2015.2509500 in the use of satellite-based data, either based on synthetic aperture radar interferometry like the suite of SRTM SIR-C products or optical images like the ASTER-GDEM, for the production of DEMs.

In 2014, the German Aerospace Center (DLR) released the first version of its intermediate DEM (IDEM) from the TanDEM-X satellite mission. This constellation of two satellites flying in a close orbit formation acquires radar images of the land surface at high spatial resolution, i.e., the stripmap mode [1]. DEM data products are being developed at 12-, 30-, and $90-\mathrm{m}$ resolution.

The $1^{\circ} \times 1^{\circ}$ DEM tiles are delivered with a number of auxiliary files. These include the height error map (HEM) providing the standard deviation (SD) of the single-point height error $\sigma_{\mathrm{HEM}}$ [2], [3]. It is the result of rigorous error propagation including the evaluation of the errors summarized in the coherence of the single interferometric images and the mosaicking process. Being considered a random error not including any systematic errors [3], the single-point height error represents the precision of the instrument or product, while ground control points are needed to estimate the absolute height error $(\Delta h)$ or the deviation from field-measured elevation data (accuracy of the measurements).

Ongoing global-scale validation efforts using ICESat validation points, kinematic GPS (KGPS) tracks with an accuracy of $<1 \mathrm{~m}$, and SRTM data have shown that the TanDEM-X products outperform the mission requirements concerning precision and accuracy in moderate terrain [4], [5]. Due to the fact that IDEM height readings are sensible to land cover, especially woody vegetation structure [6], [7], local-scale validation efforts are needed to better understand the influence of land cover on the IDEM.

\section{Materials And Methods}

\section{A. Study Sites}

The Kruger National Park (KNP), South Africa, with $20000 \mathrm{~km}^{2}$ is Africa's largest national park. It is covered by a diverse range of savanna vegetation communities with varying density of woody vegetation coexisting with grasses and forbs. The park is subject to a north-south rainfall gradient and is situated on mostly granitic (west) and basaltic bedrock (east), leading to distinct soil types that also influence the tree/grass composition [8]. Two study sites were selected for the validation: one bare soil and grassland site and one with woody vegetation. 
1) Nhlanganzwani Reservoir (Bare Soil and Grassland): This site $\left(0.35 \mathrm{~km}^{2}\right)$ is the breached (in 2007) and dried out Nhlanganzwani Reservoir located on basaltic bedrock close to the eastern border of KNP. The surface of the former reservoir $\left(0.16 \mathrm{~km}^{2}\right)$ is virtually devoid of woody vegetation, and the surrounding is characterized by a mean woody fractional cover of $25 \% \pm 10 \%(\bar{\chi} \pm \mathrm{SD})$ [9]. For this site, the IDEM elevation data were developed from two TanDEM-X stripmap acquisitions (two coverages) from February and April 2011. The single-point $\sigma_{\text {HEM }}$ ranges from 0.266 to $1.040 \mathrm{~m}$ with a mean of $0.415 \mathrm{~m}$ based on $\sim 7400$ pixel.

2) Sabie Sands Peninsula (Woody Vegetation): This site $\left(4 \mathrm{~km}^{2}\right)$ is on the granitic peninsula between the Sabie and Sand Rivers near the Skukuza rest camp. It is characterized by a mean woody fractional cover of $40 \% \pm 15 \%(\bar{\chi} \pm \mathrm{SD})$ [9]. The IDEM data set was developed from one TanDEM-X stripmap acquisition (one coverage) in January 2011. Here, the single-point $\sigma_{\mathrm{HEM}}$ ranges from 0.312 to $11.50 \mathrm{~m}$ with a mean of $0.624 \mathrm{~m}$ based on $\sim 29900$ pixels.

\section{B. Analysis Methods}

In this letter, the TanDEM-X-derived IDEM is validated on a local scale by investigating the height difference $(\Delta h)$ between the IDEM and field-measured elevation data. For the bare soil and grassland site, the reference data were acquired using differential GNSS (DGNSS), and for the second site, an airborne LiDAR data set acquired in 2007 by the University of Witwatersrand was available. DGNSS measurements from the second site served primarily cross-validation purposes.

1) DGNSS Ground Points: DGNSS ground survey points were measured in 2014 and 2015 using LEICA GS10 and GS15 GNSS receivers in real-time kinematic (RTK) mode. The base station positions at both sites were determined with reference to the South African network of permanent GNSS stations (TrigNet), resulting in a negligible uncertainty $\left(\sigma_{\mathrm{RTK}}\right)$ of $<0.03 \mathrm{~m}$ for measurements reported in height above ellipsoid (m HAE) of WGS84. To weight each IDEM pixel equally, multiple survey point samples within an IDEM pixel were averaged [10]. Thus, the $\sim 850$ individual survey points at Nhlanganzwani reservoir were reduced to 570 pixels with 0.4 arcsec resolution.

2) Airborne LiDAR: LiDAR data provided first and last return elevation and intensity values at $1-\mathrm{m}$ spatial resolution. In a first step, terrain and off-terrain points were separated using the Terrain Filter implemented in the software RiSCAN PRO Version 2.1 [11]. The data were resampled to the 12-m resolution of the IDEM data using morphological filtering. The off-terrain elevation points were aggregated using the maximum within a $12 \mathrm{~m} \times 12 \mathrm{~m}$ moving window to increase the likelihood of finding a return from the canopy top height. The terrain elevation points were aggregated using the local minimum to get a higher proportion of ground returns. To remove further residual effects of vegetation canopy height on the LiDAR data, we identified all LiDAR pixels where the height difference between the first and last returns is less than $0.1 \mathrm{~m}$. This threshold was chosen under consideration of system noise.

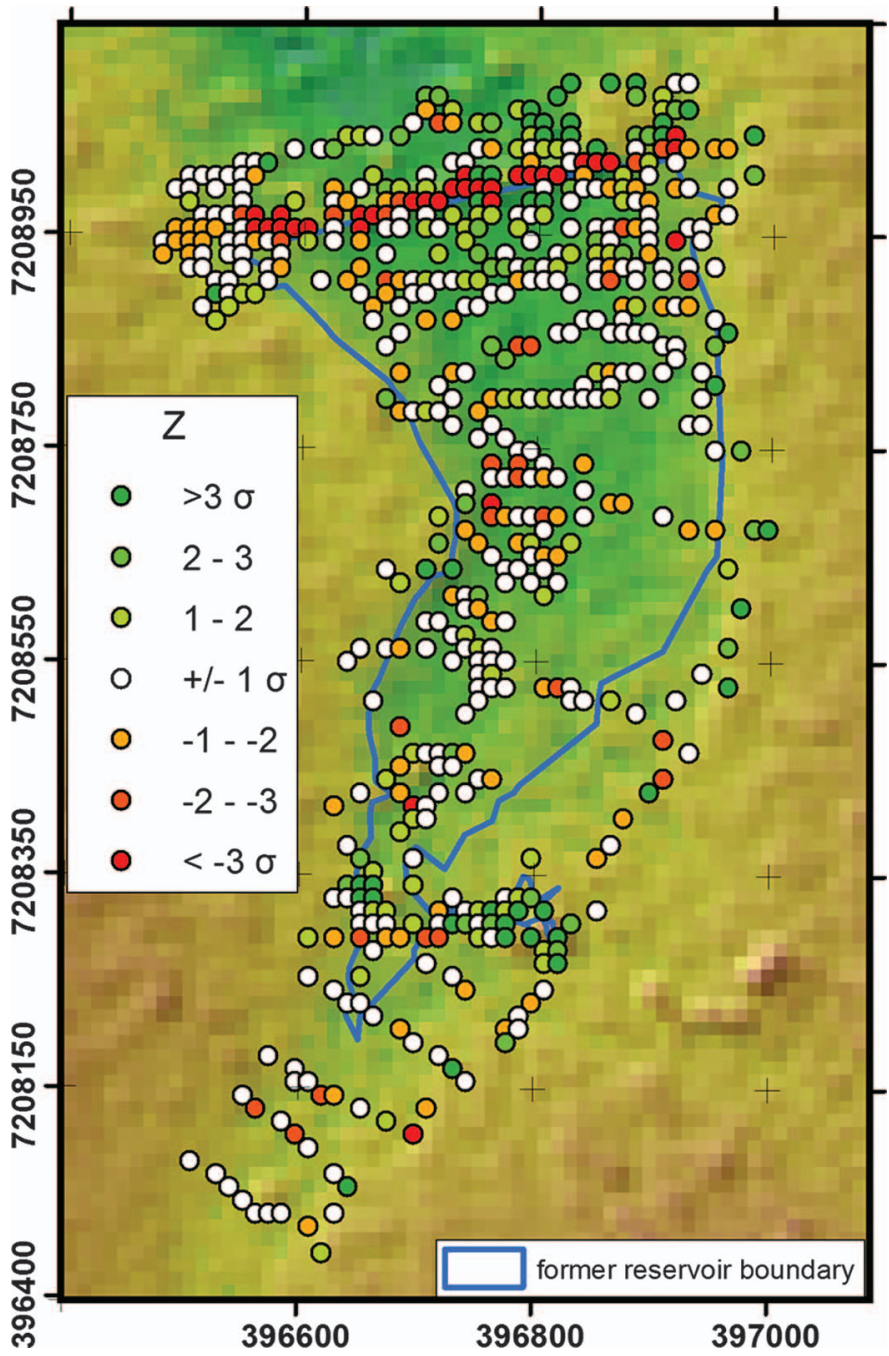

Fig. 1. Pixel-based differences of IDEM minus DGNSS ground survey point height $(\Delta h)$ related to the single-point $\sigma_{\mathrm{HEM}}[\mathrm{Z}]$ at Nhlanganzwani reservoir. Coordinates are in meters, UTM projection, Zone 36S, WGS84 Datum. The former reservoir basin is clearly recognizable from the IDEM elevation data.

3) Cross-Validation of DGNSS and Airborne LiDAR: The cross-validation of the two ground point acquisition methods used in this study was based on the comparison of DGNSS ground points with a $1-\mathrm{m}$ posting DTM derived from the LiDAR terrain points. Based on 257 GNSS points, this exercise yielded an RMSE $=0.011 \mathrm{~m}$ and a bias of $-0.023 \mathrm{~m}$, indicating deviations well below the uncertainty $\left(\sigma_{\mathrm{RTK}}\right)$ of the DGNSS measurements.

\section{RESULTS}

\section{A. Nhlanganzwani Reservoir (Bare Soil and Grassland)}

In the very open landscape of the former Nhlanganzwani reservoir, the rmse of IDEM and DGNSS point height difference $(\Delta h)$ is $0.866 \mathrm{~m}$, with a very small bias of $0.068 \mathrm{~m}(N=$ 569 ). About $46 \%$ of all pixels show a $\Delta h \leq \pm 1 \sigma_{\mathrm{HEM}}$ (Fig. 1 ). For all points located within the former reservoir boundary and characterized by grassland and bare soil only $(N=251)$, the rmse is $0.242 \mathrm{~m}$, and the bias is $-0.068 \mathrm{~m}$. Here, $58 \%$ of all pixel provides a $\Delta h \leq \pm 1 \sigma_{\mathrm{HEM}}$. Beyond this, positive 


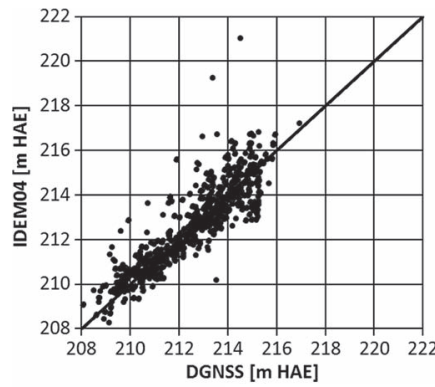

(a)

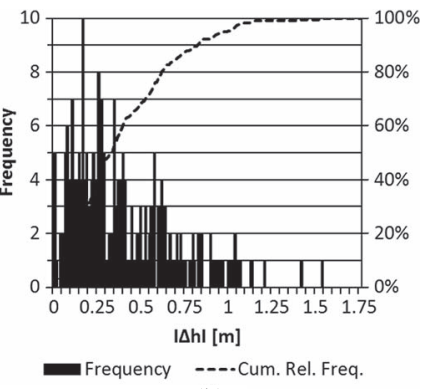

(b)
Fig. 2. (a) IDEM04 height versus DGNSS ground survey point height (resampled to IDEM raster, both in $m$ HAE) for all points from Fig. 1. (b) Histogram of absolute height difference $(I \Delta h I)$ for points from the inside of Nhlanganzwani reservoir (points close to the dam and to woody vegetation were omitted).

differences [up to $6.4 \mathrm{~m}$; Fig. 2(a)] are mostly attributable to woody vegetation at the edge and in the surrounding of the former reservoir basin. The linear concentration of pixels with extreme negative differences $\left(<-3 \sigma_{\mathrm{HEM}}\right.$, up to $\left.-3.5 \mathrm{~m}\right)$ marks the course of the earthen dam with a bottom width of up to $35 \mathrm{~m}$, a top width of $3 \mathrm{~m}$, and a maximum height of $5.5 \mathrm{~m}$. High negative deviations are obviously associated with land surface features (microrelief) being smaller than the IDEM resolution cell. However, in situations unbiased by woody cover or microrelief, the IDEM reaches submeter accuracy with $90 \%$ of all points $(N=251)$ yielding absolute errors $<0.82 \mathrm{~m}$ [Fig. 2(b)].

\section{B. Sabie Sands (Woody Vegetation)}

1) Validation of IDEM With Airborne LiDAR: Fig. 3 shows the IDEM and LiDAR last return height images of the Sabie Sands peninsula. The Sand River channel is visible at the top of the maps and the Sabie River at the bottom. The river channels only fully fill with water in the rainy season and after tropical storms and have small meandering streams interspersed with sandbanks and tall reed vegetation for the remainder of the year.

Fig. 4(a) shows the LiDAR first and last return elevation data. Many of the first and last returns are on the $1: 1$ line, but a cloud of points in the density scatterplot is above the line, where the first return is influenced by vegetation canopy height more than the last return.

After the selection of ground hits based on the $<0.1-\mathrm{m}$ height difference criterion, the first and last return points lie very close to the $1: 1$ line [Fig. 4(b)]. These first and last returns had an RMSE $=0.027 \mathrm{~m}$ and a very small bias of $0.012 \mathrm{~m}$. Only the last return heights from the terrain filtered subset of the LiDAR data were used for the following validation of the IDEM product.

Fig. 4(c) shows the IDEM validation results from the LiDAR last return terrain heights at Sabie Sands. Assuming that the LiDAR last return hits are accurate representations of the terrain surface height, the IDEM height data have an RMSE = $0.9889 \mathrm{~m}$ and a bias of $0.2381 \mathrm{~cm}$. The histogram of the deviations of the IDEM height and the LiDAR last return height over open ground is given in Fig. 4(d). Here, $99 \%$ of the deviation values is within $C I 99=[-3.2 \mathrm{~m} ; 3.6 \mathrm{~m}]$ and $95 \%$ of values within $C I 95=[-1.4 \mathrm{~m} ; 2 \mathrm{~m}]$.

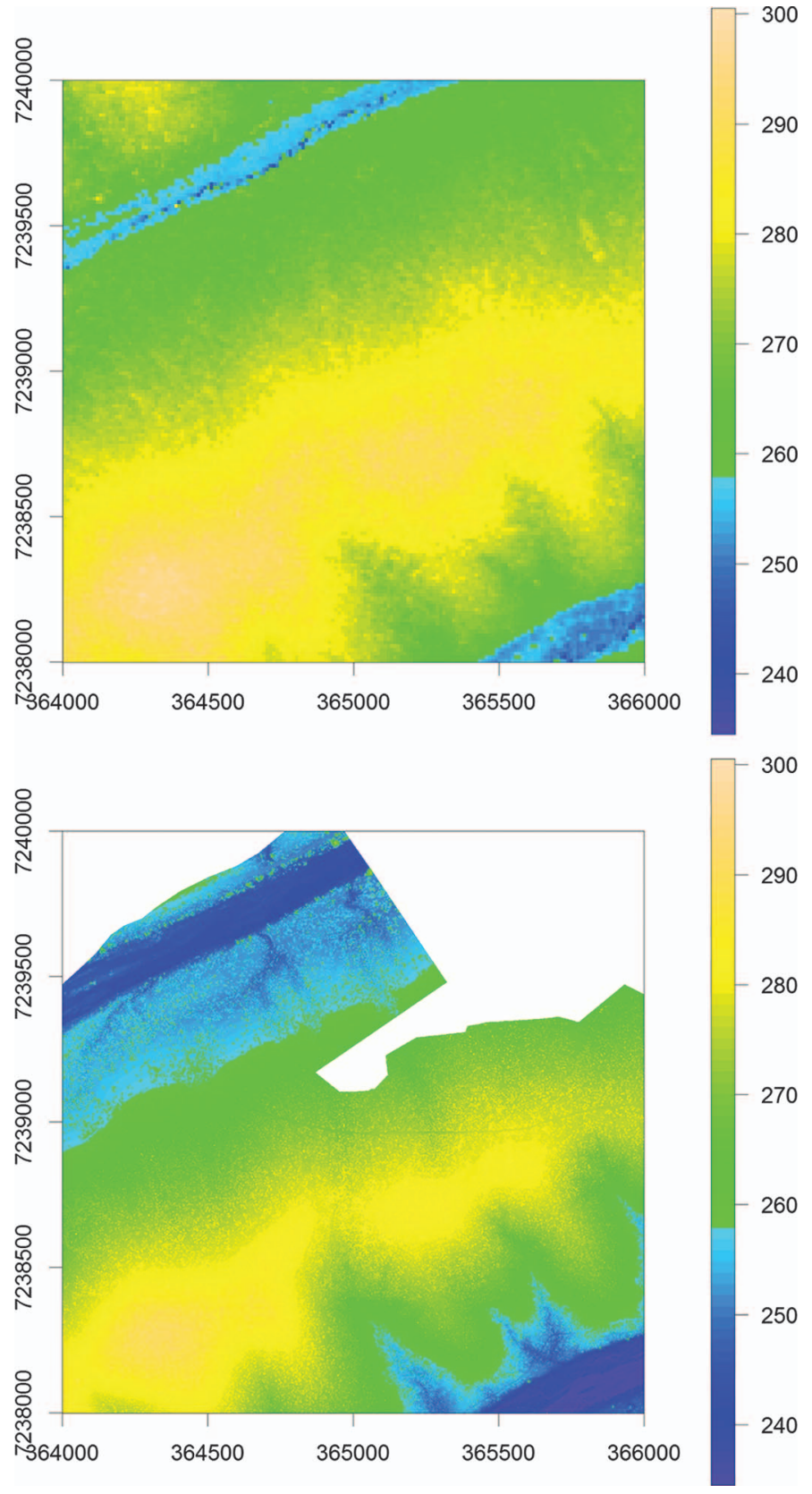

Fig. 3. TanDEM-X IDEM (top) and last return height from airborne LiDAR (bottom) in units of meters. Coordinates are in meters, UTM projection, Zone 36S, WGS84 Datum.

Microwave scattering processes are known to be influenced by the vegetation canopy due to its water content changing the dielectric constant of the target. This is particularly the case at $\mathrm{X}$-band. To understand the residual vegetation influence on the IDEM elevation data, an analysis of the vertical location of the scattering phase center height at X-band is needed.

Fig. 5(a) shows a canopy height model from the airborne LiDAR at $12-\mathrm{m}$ resolution to document the presence and structure of the vegetation. Fig. 5(b) shows a transect plot of the LiDAR first and last returns compared to the IDEM data. Fig 5(b) shows that the first and last return heights are often close to each other, even in vegetated terrain. The results show that the IDEM height is located vertically in between the terrain 


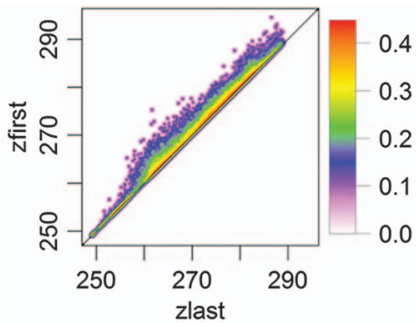

(a)

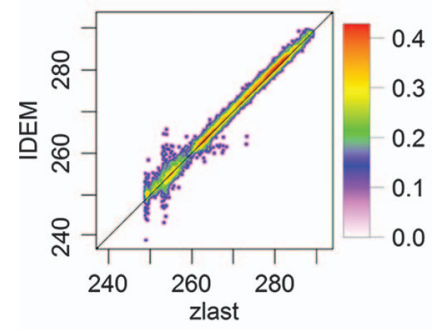

(c)

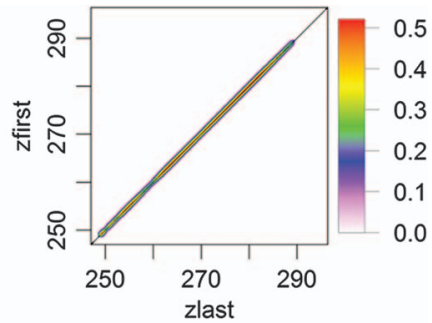

(b)

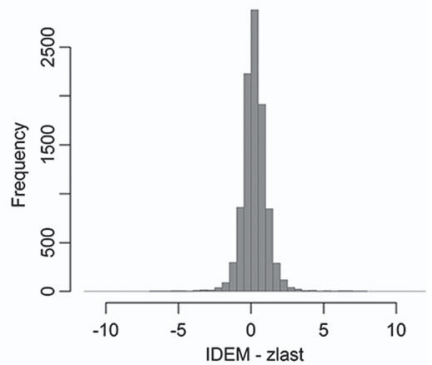

(d)
Fig. 4. (a) First versus last return height from airborne LiDAR at Sabie Sands resampled to 12-m resolution showing the influence of vegetation height on the first return. (b) First versus last return height of ground hits only. (c) Validation of IDEM using only the last return ground hits from (b). Colors in (a)-(c) are the binned 2-D kernel density estimates with a bivariate Gaussian kernel. (d) Histogram of deviations between IDEM and last return ground height in (c).

height and the vegetation canopy top height. This limits the use of unfiltered IDEM data over dense vegetation canopies when underlying terrain height is required. The vertical offset is caused by the volume scattering of $\mathrm{X}$-band radiation in the vegetation canopy.

2) Vegetation Effect on the Scattering Phase Center Height: To investigate the vegetation bias in the IDEM height estimate, which is introduced from volume scattering in the vegetation layer, the difference between vegetation canopy height in the LiDAR data set (first-last return) and the scattering phase center height from IDEM (IDEM-last return) are compared. The rmse between the two data sets is $1.36 \mathrm{~m}$. The mean canopy height from LiDAR was $1.23 \mathrm{~m}$. The mean scattering phase center height of IDEM was $0.75 \mathrm{~m}$, and the difference between the two was $0.48 \mathrm{~m}$. This indicates that the scattering phase center at X-band is located at approximately $60 \%$ of the canopy height for the patchy savanna vegetation on the Sabie Sands peninsula.

\section{Discussion AND CONCLUSION}

The local-scale validation of the TanDEM-X-derived IDEM04 product with a geometric resolution of 0.4 arcsec using a LiDAR data set and moderate terrain DGNSS-based ground survey points with a precision of $<0.05 \mathrm{~m}$ from a pristine Lowveld Savanna environment provides evidence for the high accuracy of this new and truly global DEM. With rmse values $<1 \mathrm{~m}$, the IDEM04 data set clearly fulfils the absolute vertical accuracy benchmark for the TanDEM-X mission [1] in this setting. Furthermore, our results, based on highly accurate ground point measurements, confirm on a local scale the results presented by [4] and [5] using KGPS tracks, ICESat point measures, and SRTM data for flat and mostly low vegetated terrain.
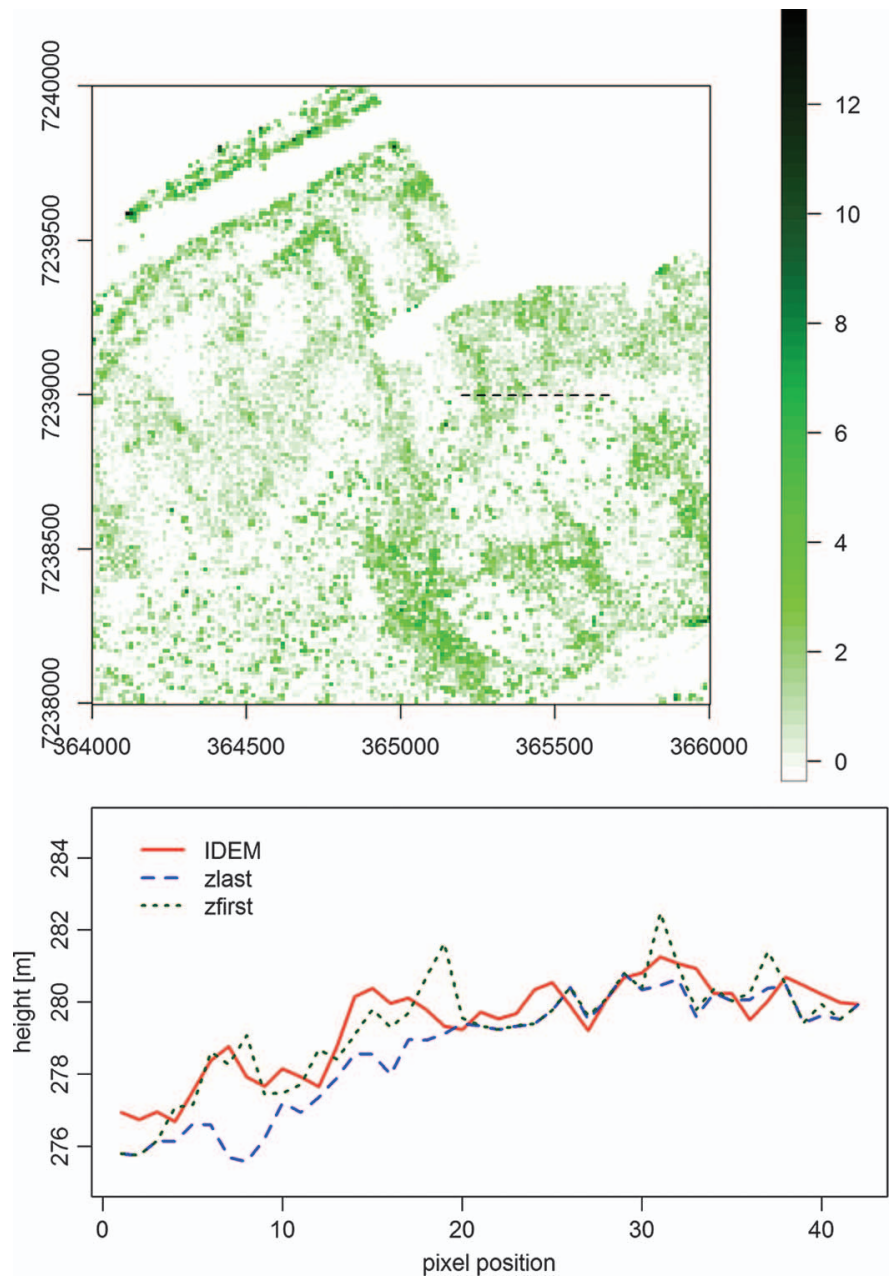

Fig. 5. (Top) Canopy height model from the first and last return LiDAR (in meters). The location of the profile transect is shown as a black dashed line. (Bottom) LiDAR first return height (green dotted line), last return height (blue dashed line), and IDEM (red solid line) along the 500-m transect.

However, the comparison with airborne LiDAR and DGNSS measurements presented here shows that, over partially vegetated terrain, the scattering phase centers at X-band are located above the terrain height. This introduces a vegetation height effect to the IDEM product. Interestingly, the location of the $\mathrm{X}$-band scattering phase center at approximately $60 \%$ of the canopy height for the patchy savanna vegetation is compared to approximately $75 \%$ found for boreal forests in Finland [12], $70 \%$ for mixed forests in Central Germany [13], and 70\%-75\% in Corsican Pine plantations of different age at Thetford forest in U.K. [6].

In conclusion, the IDEM product provides a highly accurate elevation data set at high spatial resolution over unvegetated areas but is affected by volume decorrelation and vertical displacement of the scattering phase center over areas with woody cover.

\section{ACKNOWLEDGMENT}

The authors would like to thank South African National Parks (SANParks) for the fieldwork permission and logistical support and the German Aerospace Center (DLR) for providing the TanDEM-X IDEM data. 


\section{REFERENCES}

[1] G. Krieger et al., "TanDEM-X: A radar interferometer with two formationflying satellites," Acta Astron., vol. 89, pp. 83-98, Aug./Sep. 2013.

[2] B. Wessel, "TanDEM-X Ground Segment DEM Products Specification Document," Deutsches Zentrum Luft—Und Raumfahrt (DLR), Oberpfaffenhofen, Germany, TD-GS-PS-0021, Issue 3.0, 2013.

[3] C. Gonzalez, B. Braeutigam, M. Martone, and P. Rizzoli, "Relative height error estimation method for TanDEM-X DEM products," in Proc. 10th Eur. Conf. Synthetic Aperture Radar, Berlin, Germany, 2014, pp. 1001-1004.

[4] B. Wessel et al., "Validation of the absolute height accuracy of TanDEM-X DEM for moderate terrain," in Proc. IEEE IGARSS, Quebec City, QC, Canada, 2014, pp. 3394-3397.

[5] C. Wecklich, C. Gonzalez, and B. Bräutigam, "Height accuracy for the first part of the global TanDEM-X DEM data," in Geomorphometry for Geosciences, J. Jasiewicz, Z. Zwolinski, H. Mitasova, and T. Hengl, Eds. Poznan, Poland: Poznan University, 2015, pp. 5-8.

[6] H. Balzter, A. Luckman, L. Skinner, C. Rowland, and T. Dawson, "Observations of forest stand top height and mean height from interferometric SAR and LiDAR over a conifer plantation at Thetford Forest, UK," Int. J. Remote Sens., vol. 28, no. 6, pp. 1173-1197, Mar. 2007.

[7] H. Balzter, C. S. Rowland, and P. Saich, "Forest canopy height and carbon estimation at Monks Wood National Nature Reserve, UK, using dualwavelength SAR interferometry," Remote Sens. Environ., vol. 108, no. 3, pp. 224-239, Jun. 2007.
[8] F. J. Venter, R. J. Scholes, and H. Eckhardt, "The abiotic template and its associated vegetation pattern," in The Kruger Experience: Ecology and Management of Savanna Heterogeneity, J. T. Du Toit, K. H. Rogers, and H. C. Biggs, Eds. Washington, DC, USA: Island, 2003, pp. 83-129.

[9] G. Bucini et al., "Woody fractional cover in Kruger National Park, South Africa: remote-sensing-based maps and ecological insights," in Ecosystem Function in Savannas: Measurement and Modeling at Landscape to Global Scales, M. J. Hill and N. P. Hanan, Eds. Boca Raton, FL, USA CRC Press, 2010, pp. 219-238.

[10] E. Rodriguez, C. S. Morris, and J. E. Belz, "A global assessment of the SRTM performance," Photogramm. Eng. Remote Sens., vol. 72, no. 3, pp. 249-260, Mar. 2006.

[11] RiSCAN PRO Viewer, Acquisition \& Processing Software, Vers. 2.1, Riegl Laser Measurement Systems, Horn, Austria, 2015.

[12] J. Praks, O. Antropov, and M. T. Hallikainen, "LiDAR-aided SAR interferometry studies in boreal forest: Scattering phase center and extinction coefficient at X- and L-band," IEEE Trans. Geosci. Remote Sens., vol. 50, no. 10, pp. 3831-3843, Oct. 2012.

[13] J. Baade and C. Schmullius, "Uncertainties of a TanDEM-X derived digital surface model-A case study from the Roda catchment, Germany," in Proc. IEEE IGARSS, Quebec City, QC, Canada, 2014, pp. 4327-4330. 